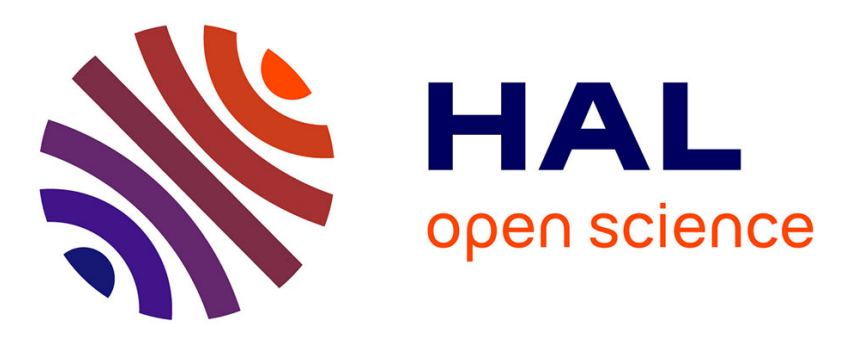

\title{
Rheological response of compressible SMCs under various deformation kinematics: Experimental aspects and simple modelling approach
}

Dimitri Ferré-Sentis, Pierre J.J. Dumont, Laurent Orgéas, Florian Martoïa, Mustafa Sager

\section{To cite this version:}

Dimitri Ferré-Sentis, Pierre J.J. Dumont, Laurent Orgéas, Florian Martoïa, Mustafa Sager. Rheological response of compressible SMCs under various deformation kinematics: Experimental aspects and simple modelling approach. Composites Part A: Applied Science and Manufacturing, 2022, 154, pp.106774. 10.1016/j.compositesa.2021.106774 . hal-03509153

\section{HAL Id: hal-03509153 https://hal.science/hal-03509153}

Submitted on 4 Jan 2022

HAL is a multi-disciplinary open access archive for the deposit and dissemination of scientific research documents, whether they are published or not. The documents may come from teaching and research institutions in France or abroad, or from public or private research centers.
L'archive ouverte pluridisciplinaire HAL, est destinée au dépôt et à la diffusion de documents scientifiques de niveau recherche, publiés ou non, émanant des établissements d'enseignement et de recherche français ou étrangers, des laboratoires publics ou privés. 


\title{
Rheological response of compressible SMCs under various deformation kinematics:
} experimental aspects and simple modelling approach

\author{
D. Ferré-Sentis ${ }^{1,2,3,4}$, P.J.J. Dumont ${ }^{3 *}$, L. Orgéas ${ }^{2}$, F. Martoïa ${ }^{3}$, M. Sager ${ }^{4}$ \\ ${ }^{1}$ Univ. Grenoble Alpes, CNRS, Grenoble INP, 3SR Lab, F-38000 Grenoble, France \\ ${ }^{2}$ Univ. Grenoble Alpes, CNRS, Grenoble INP, Agefpi, LGP2, F-38000 Grenoble, France \\ ${ }^{3}$ Univ. Lyon, INSA Lyon, CNRS, LaMCoS, UMR5259, F-69621 Villeurbanne, France \\ ${ }^{4}$ Plastic Omnium - Intelligent Exterior Systems, F-01150 Sainte-Julie, France \\ *Corresponding author's email: pierre.dumont@insa-lyon.fr
}

\begin{abstract}
KEYWORDS: E. Moulding Compounds, B. Porosity, B. Anisotropy, D. Rheology, C. Process Modelling
\end{abstract}

ABSTRACT: Flow conditions during compression moulding of Sheet Moulding Compounds (SMCs) govern the microstructure and the resulting mechanical properties of composite parts. Low-density and high-fibre content SMCs were subjected to simple compression, œdometric compression and through-thickness shear loadings, using dedicated rheometers. Simple compression and œdometric compression experiments revealed the compaction behaviour of both types of SMCs. During simple compression experiments, the compaction of low-density SMC was accompanied by in-plane elongational flow phenomena, whereas the high-fibre content SMC exhibited compaction below a characteristic axial strain and elongation and shear above. Shear tests showed that shear stress did not vary over a wide range of shear strain while being accompanied by axial compression stress. Both SMCs exhibited a shearthinning behaviour with compression viscosities that depended on the fibre volume fraction. Finally, a transversely isotropic tensorial model for SMCs seen as compressible materials was proposed. Its predictions are consistent with the experiments. 


\section{1 - Introduction}

Sheet Moulding Compounds (SMCs) are thermoset prepregs that are currently used in the aeronautics, automotive and electrical industries to manufacture semi-structural parts with cost-efficient and short processing times. Standard SMC formulations enable composite parts with good specific mechanical properties such as car body panels to be obtained. Standard formulations of SMCs are usually composed of a thermoset matrix, e.g. a polyester matrix, reinforced with 15 to $30 \mathrm{wt} \%$ of chopped glass fibre bundles. These prepregs are usually prepared in the form of sheets with a thickness that ranges between 1 and $3 \mathrm{~mm}$ [1]. SMCs are processed using compression moulding process. For that process, a charge $\left(\mathrm{T} \approx 25^{\circ} \mathrm{C}\right)$ made of several SMC layers is squeezed in a hot mould $\left(\mathrm{T} \approx 150^{\circ} \mathrm{C}\right)$ at mould closure velocities that range between 1 and $10 \mathrm{~mm} \mathrm{~s}^{-1}$. Once the mould is filled, it is maintained closed for 1 to 2 min to cure the thermoset resin. Finally, the moulded part is ejected from the mould and cooled down.

One of the current trend in the SMC industry consists in developing high-performance SMC formulations to reduce the weight of semi-structural composite parts or to manufacture structural parts. Several strategies can be employed to enhance the specific mechanical performances of SMC parts. For example, thermoset resins such as vinylester or epoxy resins with enhanced mechanical properties compared to polyester resins can be used [2], [3]. SMCs can be filled with hollow glass spheres to reduce their density [4]-[6]. Enhanced mechanical properties can also be obtained using increased fibre weight contents that exceed $50 \mathrm{wt} \%$ or using virgin or recycled carbon fibres instead of glass fibres [7]-[11].

In a recent study [5], the authors showed that the increase in the fibre content of SMC prepregs was accompanied by large modifications in the reinforcement microstructure and a strong increase in the initial pore content, leading to an increased compressibility of SMC during compression moulding. The compressibility of high-performance SMCs that can be 
related to a high pore volume fraction is of about $25 \%$, which is unusual compared to that of classical SMCs which is approximately 5\%. Hence, the use of high-performance SMC formulations in compression moulding processes lead to greater rheological problems due to their large compressibility.

Many studies focused on the mechanisms of SMC flow during compression moulding [6], [12]-[18]. The lack of process-like experimental conditions encountered in rheological studies [19]-[22] was overcome through the development of specific rheometers with large dimensions compared to the fibre bundle length and dedicated methodologies, allowing homogeneous experiments such as simple compression, plane strain compression, transverse shear to be performed [23]-[30]. These studies enabled a better understanding of SMCs rheological properties such as for instance their shear-thinning behaviour, their dependence on temperature and fibre volume fraction. Using these observations, it was possible to propose and improve some rheological models to describe the anisotropic and non-Newtonian viscous behaviour of various SMCs with a fibre content below $30 \mathrm{wt} \%$ [21], [23], [26], [28], [29]. In nearly all these models, SMC was considered to be incompressible. The resulting models were formulated using either upscaling theories [27], [31] or phenomenological approaches based on a tensorial formulation [26]. The latter phenomenological models can be easily implemented in finite element simulation codes and requires few constitutive parameters [32], [33].

Although it has been scarcely investigated, several studies have shown that even standard SMCs exhibit a rather large compressibility that is related to the porous microstructure of these prepregs [19], [34]-[36]. Some models have accounted for the compressibility of standard SMCs during their flow [29], [37], assuming a homogeneous compressible behaviour. Thus, this study aims at completing the experimental and theoretical description of the rheology of high-performance SMCs, accounting for the compressibility of these 
materials. For that purpose, two types of SMCs, namely a low-density SMC and a high fibre content SMC, were subjected to simple compression, œdometric compression and throughthickness shear loadings using dedicated rheometers. On the basis of these experimental data, a simple 3D tensorial rheological model for compressible SMCs was proposed and its predictions were compared to the experimental results.

\section{2 - Materials and methods}

\section{1 - Materials}

The rheological experiments were performed using two industrial formulations of high performance SMC with two different fibre contents. The SMC formulations were supplied by MCR (Tournon-sur-Rhône, France). The first formulation, denoted S, is typically used to fabricate lightweight semi-structural parts in the automotive industry. It consists of a polyester-based matrix reinforced with $29 \mathrm{wt} \%$ of glass fibre bundles with a $25-\mathrm{mm}$ length, a height of approximately $0.05 \mathrm{~mm}$ and a width of approximately $0.5 \mathrm{~mm}$. The second formulation, denoted $\mathrm{H}$, is used to produce structural parts for the automotive industry. It consists of a vinylester-based matrix reinforced with $50 \mathrm{wt} \%$ of glass fibre bundles (same dimensions as for the $\mathrm{S}$ formulation). To limit the dispersion of rheological measurements [30] for both SMC formulations, samples were cut in the centre part of the SMC rolls, using an automatic cutting table that enabled repeatable cutting. Particular attention was paid to limit the dispersion of the mass $m_{s}$ of the tested samples. Selected samples for the rheological experiments had a mass $m_{s}$. that was comprised in a limited range of variation, i.e., $0.97 \overline{m_{s}}<m_{s}<1.03 \overline{m_{s}}$ where $\bar{m}_{s}$ was the mean value of $m_{s}$ for the entire population of SMC samples.

\section{2 - Testing devices}

\subsection{1 - Compression device}


To study the rheology of SMCs, a specific rheometer was designed to perform simple and œdometric compression experiments (Fig. 1). As shown in Fig. 1, this rheometer was designed with a removable crown that can be installed to perform œdometric compression tests on cylindrical samples. This setup was mounted in a testing machine (Instron 5982, Elancourt, France) with a maximal translation velocity of $16 \mathrm{~mm} \mathrm{~s}^{-1}$. Before starting the compression experiments, i.e. simple compression and œdometric compression experiments, the compression platens were lubricated with silicone grease and the SMC samples were subjected to a small pre-compression stress $(0.017 \mathrm{MPa})$ to ensure the contact with the platens. After stress relaxation (i.e. after a waiting time of about $1 \mathrm{~min}$ ), the compression experiments were performed at constant strain rate $D_{33}=\frac{\dot{h}}{h}$ that ranged between $10^{-4}$ and $10^{-}$ ${ }^{1} \mathrm{~S}^{-1}$. Note that the strain rates investigated in this study correspond to those encountered by SMC charges during industrial moulding of parts. During compression experiments along the $\boldsymbol{e}_{3}$-axis, the compression force $F$ was measured using a force sensor with a load capacity of $100 \mathrm{kN}$. Compression experiments were performed at ambient temperature $\left(T \approx 20^{\circ} \mathrm{C}\right)$.

Simple compression - For simple compression experiments, the nominal stress $\Sigma_{33 s c}=\frac{F}{S_{0}}$ was calculated, $S_{0}$ being the surface of the sample in contact with the compression platens in the initial state. Assuming that this surface remained approximately constant, i.e. $S \approx S_{0}$, in the early stages of the compression experiments due to the compressibility of SMC samples, this stress was also considered to correspond to the Cauchy compression stress: $\sigma_{33 s c} \approx \Sigma_{33 s c}$ (see below for the validation of this assumption). A LVDT sensor was used to measure the vertical motion $u$ of the compression platens. From the measurements of $u$ and the initial height of the SMC samples $h_{0}$, it was possible to determine the current height $h$ of the deformed samples, i.e. $h \approx h_{0}+u$, and the compression Hencky's strain $\varepsilon_{33}=\left(h / h_{0}\right)$. Samples used for the simple compression experiments were made of two stacked discs, leading to initial sample heights $h_{0}$ that were approximately equal to 4 and $6 \mathrm{~mm}$ for the $\mathrm{H}$ 
and S SMCs, respectively. The initial diameter $D_{0}$ of the sample was set to $80 \mathrm{~mm}$ so that the macroscale strain field can be considered as homogeneous [25], [26]. To observe the evolution of the front flow geometry, a CCD camera (spatial resolution of $1624 \times 1236$ pixels and acquisition frequency of $10 \mathrm{~Hz})$ was positioned in the $\left(\boldsymbol{e}_{2}, \boldsymbol{e}_{3}\right)$ plane. For each testing condition, four samples were successively compressed. For these experiments, the Cauchy stress $\boldsymbol{\sigma}$, Hencky strain $\boldsymbol{\varepsilon}$ and strain rate $\mathbf{D}$ tensors for simple compression in the $\left(\boldsymbol{e}_{1}, \boldsymbol{e}_{2}, \boldsymbol{e}_{3}\right)$ Cartesian reference frame write as follows:

$$
\begin{array}{ll}
\boldsymbol{\sigma}_{s c}=\sigma_{33 s c} \boldsymbol{e}_{3} \otimes \boldsymbol{e}_{3} & \text { Eq. 1a } \\
\boldsymbol{\varepsilon}=\varepsilon_{11} \boldsymbol{e}_{1} \otimes \boldsymbol{e}_{1}+\varepsilon_{22} \boldsymbol{e}_{2} \otimes \boldsymbol{e}_{2}+\varepsilon_{33} \boldsymbol{e}_{3} \otimes \boldsymbol{e}_{3} & \text { Eq. 1b } \\
\mathbf{D}=\mathrm{D}_{11} \boldsymbol{e}_{1} \otimes \boldsymbol{e}_{1}+\mathrm{D}_{22} \boldsymbol{e}_{2} \otimes \boldsymbol{e}_{2}+\mathrm{D}_{33} \boldsymbol{e}_{3} \otimes \boldsymbol{e}_{3} & \text { Eq. 1c }
\end{array}
$$

Edometric compression - The experimental procedure used for œdometric compression experiments is similar to that described in the previous section for simple compression. The œdometric compression Cauchy stress was calculated as follows: $\sigma_{33 o e}=\frac{F}{S_{0}}, S_{0}$ being the (constant) surface of sample in contact with the compression platens. The lateral stress $\sigma_{11 o e}$ was measured using a pressure sensor with a capacity of $200 \mathrm{MPa}$ (Fig. 1). The signal of this sensor was synchronized with that of the press by using Labview data acquisition software. The compression Hencky strain $\varepsilon_{33}=\ln \left(\frac{h}{h_{0}}\right)$ was measured from the measurement of the vertical motion displacement $u$ provided by the LVDT sensor (Fig. 1). Samples were made of four stacked discs, leading to initial sample heights $h_{0}$ that were approximately equal to 9 and $13 \mathrm{~mm}$ for the $\mathrm{H}$ and S SMCs, respectively. The diameter $D_{0}$ of the sample was set to $120 \mathrm{~mm}$ in order to maximize the sample size, while allowing a pressure representative of the process $(8.8 \mathrm{MPa})$ to be applied. The Cauchy stress $\boldsymbol{\sigma}$, Hencky strain $\boldsymbol{\varepsilon}$ and strain rate $\boldsymbol{D}$ tensors for oedometric compression in the Cartesian reference frame $\left(\boldsymbol{e}_{1}, \boldsymbol{e}_{2}, \boldsymbol{e}_{3}\right)$ read:

$\boldsymbol{\sigma}_{o e}=\sigma_{11 o e}\left(\boldsymbol{e}_{1} \otimes \boldsymbol{e}_{1}+\boldsymbol{e}_{2} \otimes \boldsymbol{e}_{2}\right)+\sigma_{33 o e} \boldsymbol{e}_{3} \otimes \boldsymbol{e}_{3}$ Eq. $2 \mathrm{a}$ 
$\boldsymbol{\varepsilon}=\varepsilon_{33} \boldsymbol{e}_{3} \otimes \boldsymbol{e}_{3}$

Eq. $2 b$

$\boldsymbol{D}=\mathrm{D}_{33} \boldsymbol{e}_{3} \otimes \boldsymbol{e}_{3}$

Eq. $2 \mathrm{c}$

Volume variations of SMC samples - For both types of compression experiments, it was necessary to estimate the volume variations of SMC samples so as to investigate the effect of the fibre volume fraction on the rheological response of both SMCs. Assuming that the volume variation was entirely due to the "evacuation" of pores (Figs. 6a,b), i.e., that the matrix and the fibre bundles were incompressible or that their volume was constant, the solid volume fraction $\phi_{\mathrm{m}}$ was defined as follows:

$\phi_{\mathrm{m}}=\frac{\mathrm{V}_{\mathrm{m}}}{\mathrm{V}}$

where $V_{m}$ and $V$ were the volume of the solid phase (matrix plus fibres) and the total volume of the samples, respectively. By applying the continuity equation,

$\operatorname{div} \boldsymbol{v}=-\dot{\rho} / \rho=\dot{\varepsilon}_{V}$ Eq. 4 where $\boldsymbol{v}, \rho$ and $\dot{\varepsilon}_{V}$ are the velocity field, the SMC density, the rate of change of the SMC density and the rate of change of the volumetric strain rate, respectively, and assuming that the SMC volume variations were spatially homogeneous and isotropic, it can be shown that:

$\left\{\begin{array}{c}\phi_{\mathrm{m}}=\phi_{\mathrm{m} 0} \cdot \mathrm{e}^{-\left|\varepsilon_{V}\right|} \\ \phi_{\mathrm{p}}=1-\phi_{\mathrm{m} 0} \cdot \mathrm{e}^{-\left|\varepsilon_{V}\right|} \\ \phi_{\mathrm{f}}=\varphi_{\mathrm{f}} \phi_{\mathrm{m} 0} \cdot \mathrm{e}^{-\left|\varepsilon_{V}\right|}\end{array}\right.$

where $\varepsilon_{V}$ is the volumetric strain, defined as $\varepsilon_{V}=\ln \left(\frac{V}{V_{0}}\right)$ with $V_{0}$ the initial volume, $\phi_{m 0}$ the initial solid volume fraction, $\phi_{p}$ the pore volume fraction, $\phi_{f}$ the fibre volume fraction, and $\varphi_{f}$ the fibre volume fraction in the solid phase. The evolution of $\phi_{f}$ as a function of $\varepsilon_{V}$ was obtained from the results of a previous study dedicated to the study of the compressibility of the S and H SMCs [5]. This evolution is shown for both compression kinematics in Figs. 6b,c.

\subsection{1 - Shearing device}


The shear tests were performed using a 3D servo-controlled direct shear machine called BCR3D (Fig. 2a) [38]. This machine enabled dynamic shear tests to be performed up to a maximal translation speed of $0.5 \mathrm{~mm} \mathrm{~s}^{-1}$, while applying a maximum normal force of $100 \mathrm{kN}$. The principle of the shear test is schematized in Figs. 2b,c. The SMC samples were placed between an upper and a lower platens coated with sandpaper. During shearing, the upper and lower platens of the machine had a symmetrical movement, while the normal force remained centred on the sample at any time. The shear velocity was imposed using brushless motors (one for the normal-vertical direction and two for each tangential-horizontal direction) and a PID computer control. In this experiment, only 3 of the 5 motors were used and the applied shear was restricted to the $\left(\boldsymbol{e}_{1}, \boldsymbol{e}_{3}\right)$ plane. Three LVDT sensors enabled the measurement of the displacements $u_{i}(i=\{1,3\})$ of the platens in the $\boldsymbol{e}_{1}$ and $\boldsymbol{e}_{3}$ directions. These measurements were used to determine the shear strain $\varepsilon_{13}=\frac{1}{2}\left(u_{1}+u_{1}^{\prime}\right) / h=\gamma_{13} / 2$ (Figs. $2 \mathrm{~b}, \mathrm{c})$ and the Hencky strain $\varepsilon_{33}=\ln \left(\frac{h}{h_{0}}\right)$. The three load cells (load capacity of $100 \mathrm{kN}$ ) enabled the normal force exerted on each platen to be measured. Then, the normal stress $\sigma_{33 s}=\frac{F_{3}}{S}$ and the shear stress $\sigma_{13 s}=\frac{F_{1}+F_{1}^{\prime}}{S}$ were calculated, $S$ being the surface of the sample in the $\left(\boldsymbol{e}_{1}, \boldsymbol{e}_{2}\right)$ plane. For these experiments, samples were made of one SMC layer with inplane dimensions $120 \times 120 \mathrm{~mm}^{2}$.

Vertical and parallel lines that were spaced $20 \mathrm{~mm}$ apart were drawn with a felt pen on the side walls of the SMC sample to obtain information about the homogeneity of the displacement field in the sample (Fig. 2). The samples were placed on a sandpaper where markers that were also spaced $20 \mathrm{~mm}$ apart were drawn to verify the absence of slippage during the test. Then, the upper platen was lowered until an initial given normal stress $\sigma_{33 s}^{0}$ was reached. Finally, the vertical displacement in the $\boldsymbol{e}_{3}$-direction was locked during the shear test. Different initial normal stresses that ranged from 0.017 to $2 \mathrm{MPa}$ were applied on the 
samples, leading to initial sample heights $h_{0}$ that ranged from 1 to $3 \mathrm{~mm}$ for both types of SMS's. After stress relaxation $(\approx 1 \mathrm{~min})$, the displacement of the upper and lower platens in the $e_{1}$-direction was applied. The tests were performed at constant shear strain rates $D_{13}=$ $\frac{1}{2}\left(\dot{u}+\dot{u}^{\prime}\right) / h=\dot{\gamma}_{13} / 2$ that ranged between $4 \cdot 10^{-3}$ and $3 \cdot 10^{-1} \mathrm{~s}^{-1}$.

Considering that the thickness $h$ of the sample was very small compared to its in plane dimensions, the Cauchy stress $\boldsymbol{\sigma}$, strain $\boldsymbol{\varepsilon}$ and strain rate $\boldsymbol{D}$ tensors for shear tests in the $\left(\boldsymbol{e}_{1}, \boldsymbol{e}_{2}, \boldsymbol{e}_{3}\right)$ Cartesian reference frame are given as follows:

$$
\begin{array}{ll}
\boldsymbol{\sigma}_{s}=\sigma_{11 s} \boldsymbol{e}_{1} \otimes \boldsymbol{e}_{1}+\sigma_{13 s}\left(\boldsymbol{e}_{1} \otimes \boldsymbol{e}_{3}+\boldsymbol{e}_{3} \otimes \boldsymbol{e}_{1}\right)+\sigma_{22 s} \boldsymbol{e}_{2} \otimes \boldsymbol{e}_{2}+\sigma_{33 s} \boldsymbol{e}_{3} \otimes \boldsymbol{e}_{3} \text { Eq. } 6 \mathrm{a} \\
\boldsymbol{\varepsilon}=\varepsilon_{13}\left(\boldsymbol{e}_{1} \otimes \boldsymbol{e}_{3}+\boldsymbol{e}_{3} \otimes \boldsymbol{e}_{1}\right) & \text { Eq. } 6 \mathrm{~b} \\
\boldsymbol{D}=\mathrm{D}_{13}\left(\boldsymbol{e}_{1} \otimes \boldsymbol{e}_{3}+\boldsymbol{e}_{3} \otimes \boldsymbol{e}_{1}\right) & \text { Eq. } 6 \mathrm{c}
\end{array}
$$

\section{3 - Results and discussion}

\section{1 - Stress-strain curves for the various tested kinematics}

The typical aspect of the stress-strain curves obtained for simple compression and œdometric compression tests is shown in Fig. 3a. From this figure several remarks can be drawn. Simple compression curves showed three different regimes: (i) a slow increase in the axial stress $\sigma_{33 s c}$ combined with a compaction of the SMC sample corresponding to the evacuation of a large amount of pores between points 0 and 1, (ii) an increase in the axial stress $\sigma_{33 s c}$ related to the beginning of the flow in the $\left(\boldsymbol{e}_{1}, \boldsymbol{e}_{2}\right)$-plane between points 1 and 2, and (iii) a slower increase in the stress $\sigma_{33 s c}$ corresponding to the flow in the $\left(\boldsymbol{e}_{1}, \boldsymbol{e}_{2}\right)$-plane above point 2. Considering the evolution of the axial stress $\sigma_{33 \text { oe }}$ observed during oedometric compression experiments (Fig. 3a), one can see that it deviated from that of the simple compression at point number 1 and that the increase in the stress $\sigma_{33 o e}$ was then very sharp. This point also marked the beginning of the very sharp increase in the lateral stress $\sigma_{11 o e}$. 
The typical aspect of the stress-strain curves obtained for the shear tests is shown in Fig. $3 \mathrm{~b}$. The dotted lines represent the evolution of the axial stress $\sigma_{33 s}$ as a function of the shear strain $\varepsilon_{13}$ after a precompaction $\sigma_{33 s}^{0}$ equal to $0.8 \mathrm{MPa}$ and $0.55 \mathrm{MPa}$ and after one minute of relaxation for the SMC S and $\mathrm{H}$, respectively. The axial stress remained constant, showing that there was no dilatancy during shearing. This observation tends to show that the elastic energy, e.g. related to the deformation of the fibre bundle network, was certainly stored in the SMC sample during the pre-compaction phase. For both types of SMC formulations, the stress-strain curves obtained for the shear tests exhibited two distinct flow regimes: (i) a transient flow regime corresponding to an increase in the shear stress $\sigma_{13 s}$ between points 0 and 1 , and (ii) a steady flow regime where the shear stress $\sigma_{13 s}$ reached a plateau above point 1. This behaviour was different from that reported by Le Corre et al. [25] who observed a stress peak followed by a slight decrease after a shear strain $\varepsilon_{13}$ of 1 . This phenomenon could be presumably associated to the heterogeneity of the shear kinematics of these former experiments which were carried out using an annular SMC disk sheared between two rotating platens with large diameters. Hence, the present experimental setup can be considered to enhance the quality of the through-thickness shear tests and the reliability of the gained results. Note that, in the following, results and discussion concerning shear stress are given for the threshold stresses, i.e., those measured during the steady state flow regime (after point 1). To verify the homogeneity of the flow for simple compression experiments, the edges of the samples were marked using paint-lines (Fig. 4). In the case of SMC S, the paint-lines were found to remain at the edges of the sample in the end of the test which confirmed the absence of friction between the sample and the compression. Further, the sample remained cylindrical (Fig. 4b). This absence of preferential direction for the flow confirmed the homogeneity of the kinematic field in the $\left(\boldsymbol{e}_{1}, \boldsymbol{e}_{2}\right)$-plane given in Eq. 1. The results are different for the $\mathrm{H}$ formulation (Figs. 4c,d). As shown in Fig. 4d, the position of the paint-line was very close to 
that of its initial position, indicating perfect sticking conditions and a heterogeneous flow kinematics that resulted from combined shear and elongation mechanisms. Thus, these conditions were very far from the sought homogeneous flow conditions. Thus, the strain field and the stress tensor were different from those given in Eq. 1. In addition, the use of a camera coupled to the compression device enabled the evolution of the flow front to be observed during simple compression experiments and, thus, the flow conditions to be clarified. As shown in Fig. 5 for a H SMC sample, the test started with a very pronounced compaction phase up to an axial strain $\left|\varepsilon_{33}\right| \approx 0.3$ during which there was no flow in the $\left(\boldsymbol{e}_{1}, \boldsymbol{e}_{2}\right)$-plane. This early stage corresponded to the evacuation of a large amount of pores (Fig. 6b) and was associated with a sharp decrease in the volume of the sample [26]. Thus, until an axial strain $\left|\varepsilon_{33}\right| \approx 0.3$, it was possible to consider that the samples were homogeneously deformed and that the Cauchy stress $\boldsymbol{\sigma}$, Hencky strain $\boldsymbol{\varepsilon}$ and strain rate $\boldsymbol{D}$ tensors were similar to those obtained for the oedometric compression. Above this strain value, elongation deformation modes were coupled with shear deformation modes. Note that for the S SMC samples, a large decreased in the SMC porosity was observed up to a simple compression strain $\left|\varepsilon_{33}\right| \approx 0.1$ [5]. In addition, the flow of the $\mathrm{S}$ formulation was elongational and no pronounced sticking phenomena to the compression platens were observed (Fig. 4).

Finally, Fig. $6 \mathrm{c}$ shows the evolution of the porosity $\phi_{p}$ as a function of the volumetric strain $\left|\varepsilon_{V}\right|$ for the $\mathrm{S}$ and $\mathrm{H}$ formulations during simple compression using experimental data provided in [5]. This figure shows that for both types of SMC formulations the evolution of the pore volume fraction $\phi_{\mathrm{p}}$ during the compaction phase is well fitted by the theoretical evolution of $\phi_{p}$ given in Eq. 5 , considering that $\varepsilon_{V} \approx \varepsilon_{33}$ during this phase.

\section{2 - Effect of the strain rate}


S formulation - For all tested deformation kinematics, the influence of the strain rate on the measured stresses could be well fitted using a power law function as shown for various fibre volume fractions $\phi_{\mathrm{f}}($ Fig. 7):

$\sigma_{\text {iiexp }}=\eta_{\text {iiexp }}\left(\phi_{\mathrm{f}}\right)\left(\frac{D_{i i}}{D_{0}}\right)^{n-1} D_{i i}$

with $\sigma_{\text {iiexp }}=\sigma_{33 s c}, \eta_{\text {iiexp }}=\eta_{33 s c}, D_{i i}=D_{33}$ for simple compression, $\sigma_{\text {iiexp }}=\sigma_{33 o e}$

$\left(\sigma_{\text {iiexp }}=\sigma_{110 e}\right), \eta_{\text {iiexp }}=\eta_{33 o e}\left(\eta_{\text {iiexp }}=\eta_{11 o e}\right), D_{i i}=D_{33}$ for œdometric compression axial stress (lateral stress), $\sigma_{\text {iiexp }}=\sigma_{13 s}$ and $\eta_{\text {iiexp }}=\eta_{13 s}$ for shear tests. The viscosities $\eta_{\text {iiexp }}$ are defined for a reference axial strain rate $D_{0}=1 \mathrm{~s}^{-1}$ and $n$ is the strain rate sensitivity index. It is interesting to note that, regardless of the fibre volume fraction $\phi_{\mathrm{f}}$, the value of the strain rate sensitivity index $n$ was constant and equal to 0.42 over the tested strain rate range and for all kinematics. This index was close to that obtained by other authors for standard SMC formulations [24], [25]. On the contrary, the compression viscosities depended on the fibre volume fraction $\phi_{\mathrm{f}}$ : the viscosity $\eta_{33 s c}$ ranged between 0.37 and $2.7 \mathrm{MPa} . \mathrm{s}^{\mathrm{n}}$, whereas the viscosities $\eta_{11 o e}$ and $\eta_{33 o e}$ ranged between 5.2 and $17 \mathrm{MPa} . \mathrm{s}^{\mathrm{n}}$ and 1.3 and $8 \mathrm{MPa} . \mathrm{s}^{\mathrm{n}}$, respectively. For shear tests, the influence of the fibre volume fraction $\phi_{\mathrm{f}}$ was not as pronounced as for compression loading cases. The shear viscosity $\eta_{13 s}$ was approximately 0.3 $\mathrm{MPa} \mathrm{s}^{\mathrm{n}}$ for all tested fibre volume fractions $\phi_{\mathrm{f}}$.

H formulation - The overall behaviour highlighted for the $\mathrm{S}$ formulation was also valid for the $\mathrm{H}$ - formulation. The evolution of the axial stresses obtained from simple compression and œdometric compressions were well described by power law functions of the axial strain rate with a strain rate sensitivity index $n=0.35$ (Fig. 8). However, the overall tendency for the evolution of the lateral stress in œdometric compression was not clear (Fig. 8c). This behaviour could be related to both the particular behaviour of the $\mathrm{H}$ formulation as well as to a technical limitation of the oedometric compression device. It was observed in the images of 
Figs. 5c and 5d that above an axial strain of approx. 0.3, the in-plane flow of the $\mathrm{H}$ formulation was rather heterogeneous through the sample thickness. Even though these images were obtained for simple compression experiments, it can be imagined that a similar effect could occur during the oedometric compression experiments. Consequently, as the pressure sensor of the oedometric compression device was located close to the bottom platen of this device, it was possible that the start of the rise of the $\sigma_{110 e}$ stress was not perfectly captured for all the oedometric compression experiments performed with the $\mathrm{H}$ formulation. The viscosity in simple and œdometric compression ranged between 0.6 and $6 \mathrm{MPa} \cdot \mathrm{s}^{\mathrm{n}}$ and 1.2 to $12 \mathrm{MPa} . \mathrm{s}^{\mathrm{n}}$, respectively, for the tested strain rates. Similarly, the shear stress was a power law function (Eq.7) of the strain rate with a strain rate sensitivity index $n$ close to 0.35 and a shear viscosity $\eta_{13 c i s}$ that ranged between 0.2 and $0.45 \mathrm{MPa} . \mathrm{s}^{\mathrm{n}}$ for all tested fibre volume fractions $\phi_{\mathrm{f}}$.

\section{4 - A non-linear viscous and transversely isotropic rheological model for compressible}

\section{SMCs}

Based on the various experimental results gathered in this study together with those reported in ref. [5], we propose a simple rheological model for the description of the viscous stress tensor of SMCs seen as one-phase compressible materials. The modelling strategy is similar to that adopted in several previous studies where a phenomenological constitutive equation for SMCs was deduced from rheological data obtained at the macroscale [26], [28], [39], [40]. In this approach, it is assumed that SMCs are purely viscous material. Thus, the stress tensor $\boldsymbol{\sigma}$ writes as follows:

$$
\begin{array}{ll}
\boldsymbol{\sigma}=\boldsymbol{\sigma}^{v} & \text { Eq. } 8
\end{array}
$$

where $\boldsymbol{\sigma}^{v}$ is the viscous tensor which depends on the strain rate tensor $\boldsymbol{D}$. By analogy with the expressions proposed by Dumont et al. [26] for incompressible SMCs, the stress tensor $\boldsymbol{\sigma}^{v}$ is 
assumed to be the gradient of a viscous dissipation potential $\Omega$ with respect to the strain rate tensor $\boldsymbol{D}$ :

$$
\boldsymbol{\sigma}^{v}=\frac{\partial \Omega}{\partial \boldsymbol{D}}
$$

where $\Omega$ is positive and convex and is equal to zero when $\boldsymbol{D}=\mathbf{0}$, so that:

$$
\left.\frac{\partial \Omega}{\partial \boldsymbol{D}}\right|_{\boldsymbol{D}=0}=\boldsymbol{\sigma}^{v}(\boldsymbol{D}=0)=\mathbf{0}
$$

It is assumed that $\Omega$ is a function of an equivalent strain rate $D_{e q}$, which implies that:

$$
\boldsymbol{\sigma}^{v}=\frac{\partial \Omega}{\partial D_{e q}} \frac{\partial D_{e q}}{\partial \boldsymbol{D}}=\sigma_{e q} \frac{\partial D_{e q}}{\partial \boldsymbol{D}}=\eta_{e q}\left(D_{e q}\right) D_{e q} \frac{\partial D_{e q}}{\partial \boldsymbol{D}}
$$

where $\sigma_{e q}=\eta_{e q} D_{e q}$ is an equivalent stress and $\eta_{e q}$ represents an equivalent viscosity that accounts for the global phenomenological viscous behaviour of SMCs. Using the theory of representation of anisotropic tensor functions [41], the following new quadratic form is proposed for $D_{e q}$ :

$$
D_{e q}^{2}=\alpha_{0}\left(\boldsymbol{D}: \boldsymbol{D}+\alpha_{1}(\boldsymbol{M}: \boldsymbol{D})^{2}+\alpha_{2}(\boldsymbol{D} \cdot \boldsymbol{M}): \boldsymbol{D}+\alpha_{3}(\boldsymbol{\delta}: \boldsymbol{D})^{2}\right),
$$

where the parameters $\alpha_{i}$ are rheological functions that depend on the fibre volume fraction $\phi_{\mathrm{f}}$, and $\boldsymbol{M}=\boldsymbol{e} \otimes \boldsymbol{e}$ is a structure tensor characterizing the transverse isotropy of SMCs with the axis e normal to the plane of the sheet, i.e., the plane of preferential orientation of fibres [26]. In comparison with former models, $\alpha_{3}$ is an additional rheological parameter associated to the volumetric strain rate $\boldsymbol{D}: \boldsymbol{\delta}$ that accounts for the compressibility of SMCs. As shown previously, the viscosity of SMCs is generally a power-law function of the strain rate, thus the following scalar form is chosen for $\eta_{e q}$ :

$$
\eta_{e q}=\eta\left(\frac{D_{e q}}{D_{0}}\right)^{n-1}
$$

with $D_{0}$ a reference strain rate (e.g. $D_{0}=1 \mathrm{~s}^{-1}$ ). Hence, the associated stress tensor is expressed as follows: 


$$
\boldsymbol{\sigma}^{v}=\alpha_{0} \eta_{e q}\left(\boldsymbol{D}+\alpha_{1}(\boldsymbol{M}: \boldsymbol{D}) \boldsymbol{M}+\frac{1}{2} \alpha_{2}(\boldsymbol{D} \cdot \boldsymbol{M}+\boldsymbol{M} \cdot \boldsymbol{D})+\alpha_{3}(\boldsymbol{\delta}: \boldsymbol{D}) \boldsymbol{\delta}\right), \quad \text { Eq. } 14
$$

Note that this model relates all volume variations to isotropic stress variations.

In addition, several micromechanical approaches dedicated to the prediction of the rheology of highly concentrated fibre suspensions, as for example those developed by Toll and Månson [42], Servais et. al. [43], Le Corre et al. [27] are based on the assumption that the connectivity of fibre bundle networks can be described by the statistics of the tube model [44]. This was experimentally verified using 3D imaging techniques by Orgéas et. al. [45] and Guiraud et. al. [46] for planar fibre suspensions, showing similar fibrous microstructures to those of SMCs. Hence, in these micro-macro upscaling models, all the components of the viscous stress tensor are quadratic functions of the fibre volume fraction $\phi_{\mathrm{f}}$. This result leads to choose the following form for $\eta=\eta_{0}\left(\phi_{\mathrm{f}}-\phi_{\mathrm{c}}\right)^{2}$ with $\phi_{\mathrm{c}}$ a critical fibre volume fraction below which the fibrous network is no longer cohesive. Finally, the stress tensor (Eq. 14) is written as follows:

$$
\boldsymbol{\sigma}^{v}=\alpha_{0} \eta_{0}\left(\phi_{f}-\phi_{c}\right)^{2}\left(\frac{D_{e q}}{D_{0}}\right)^{n-1}\left(\boldsymbol{D}+\alpha_{1}(\boldsymbol{M}: \boldsymbol{D}) \boldsymbol{M}+\frac{1}{2} \alpha_{2}(\boldsymbol{D} \cdot \boldsymbol{M}+\boldsymbol{M} \cdot \boldsymbol{D})+\alpha_{3}(\boldsymbol{\delta}: \boldsymbol{D}) \boldsymbol{\delta}\right)
$$

Eq. 15

with, as in the aforementioned incompressible cases, the following expressions for the rheological functions $\alpha_{i}(i=\{0,1,2\})$ :

$$
\alpha_{0}=\frac{2}{1+2 H}, \alpha_{1}=1+H-2 \frac{1+2 H}{3 L}, \alpha_{2}=2\left(\frac{1+2 H}{3 L}-1\right) .
$$

It is interesting to note that this model is consistent with the general framework proposed by Guiraud et al. [29] for the flow modelling of SMCs, regardless of their compressibility or not.

\section{3 - Identification of model parameters}

\subsection{1 - Simplification assumptions}

Taking into account the previous assumptions, six model parameters had to be identified, i.e., the viscosity $\eta_{0}$, the strain rate sensitivity $n$, the critical fibre content $\phi_{\mathrm{c}}$ and the three 
anisotropic rheological functions $H, L$ and $\alpha_{3}$. For the model identification, it was assumed that the rheological functions $H, L$ and $\alpha_{3}$ followed similar trends to those reported in several studies dedicated to the rheology of SMCs. For a standard SMC formulation, Dumont et al. [26] have shown that, over a wide range of fibre volume fractions $\left(0<\phi_{\mathrm{f}} \leq 18.8 \%\right)$ the rheological function $H$ can be considered as a constant and equal to 0.5 . Thus, this value was chosen for $H$ in this study for both SMC formulations. Similarly, it was also assumed that $L$ was constant, regardless of the fibre volume fraction $\phi_{\mathrm{f}}$. The methodology used to determine the value of $L$ is discussed in sub-section 4.3.4.

\subsection{2 - Determination of $\phi_{c}$}

The critical fibre volume fraction $\phi_{\mathrm{c}}$ was estimated by numerically generating elementary volumes of fibrous media that were representative of the fibrous microstructures of both studied SMCs. For that, the geometrical parameters for the SMC bundles were used as input parameters in a numerical microstructure generation process similar already described in Le

Corre et. al. [27] and Dumont et al. [47]. The analysis of the as-generated fibrous microstructures showed that the number of fibres with two or more contacts tended to zero for $\phi_{\mathrm{c}}=0.02$.

\subsection{3 - Determination of $\alpha_{3}$}

In the following sections, it was assumed that for the identification of the model parameters the SMC volume variation was spatially homogeneous and isotropic. This can be seen as a strong assumption, considering the rather complex spatial distribution of pores in SMCs, the anisotropic nature of these materials and the complex shape evolution of pores, as shown in a previous study [5]. Results of œdometric compression experiments were used to fit the evolution of $\alpha_{3}$ as a function of the fibre volume fraction $\phi_{\mathrm{f}}$, using Eqs. 20-22 (S1). The experimental results are reported in Fig. 9 for both SMC formulations where the dotted lines represent the interpolation that has been used to fit the evolution of $\alpha_{3}$ as follows: 


$$
\alpha_{3}=-\frac{\delta}{2}\left(\left(-\phi_{\mathrm{f}}-\varphi_{\mathrm{f}}\right)-\sqrt{\left(\phi_{\mathrm{f}}-\varphi_{\mathrm{f}}\right)^{2}+\beta^{2}}\right)-\delta \varphi_{\mathrm{f}}+\alpha_{3}^{0} \quad \text { Eq. } 17
$$

where $\alpha_{3}^{0}$ is the value of the horizontal asymptote, $\delta$ is the vertical slope in the linear part, $\beta$ the curvature.

\subsection{4 - Determination of $L, \eta_{0}$ and $n$}

The parameters $L, \eta_{0}$ and $n$ were determined using the following methodology. First, for a given fibre content $\phi_{\mathrm{f}}$, i.e., a given $\alpha_{3}$ and a given SMC formulation, the value of $L$ was adjusted by "aligning" all experimental $\sigma_{e q}-D_{e q}$ points using the results of simple compression, œdometric compression and shear experiments obtained at various strain rates for the estimates of $\sigma_{e q}$ and $D_{e q}$. Then, the values of $\eta_{0}$ and $n$ were adjusted in order to fit the model prediction with the experimental data.

Fig. 10 shows that the model could reproduce the experimental evolutions that were obtained for both the $\mathrm{S}$ and $\mathrm{H}$ formulations and for various fibre contents. Note that the model could particularly well predict the shear experimental data, which is presumably due to the aforementioned identification strategy for the $L$ parameter. The values of the different model parameters for both SMCs are given in Tab. 1. Note that the strain rate sensitivity index $n$ values were similar to those reported by Dumont et. al. [26] and Le Corre et. al.[25] for a standard SMC formulation. Finally, Fig. 11 shows a comparison between the model predictions for the evolution of the stress components as a function of the fibre volume fraction $\phi_{\mathrm{f}}$ and the experimental results that were obtained for all loading conditions for both SMC formulations. The evolution of the fibre volume fraction $\phi_{\mathrm{f}}$ was updated during compression, using for that the mass balance Eq. 4. Note that the model could rather well predict the evolution of the various stress components for this large set of experimental conditions.

\section{5 - Conclusion}


This study focused on the rheological properties of a low-density SMC and a high-fibre content SMC. Two original rheometry devices were designed to study the compressibility of both types of SMCs for flow conditions representative of the compression moulding process. Compression tests showed the large compressibility of both SMC formulations, particularly of the high fibre content SMC. For simple compression experiments, the high-fibre content formulation exhibited compaction below a characteristic axial strain. Above this characteristic strain, this type of SMC exhibited flow phenomena that coupled elongation and shear phenomena. The low-density SMC exhibited different flow phenomena. Compaction phenomena also occurred for this formulation. However, these phenomena were accompanied by pronounced in-plane elongational flow phenomena. Edometric compression experiments were well adapted to measure the compaction of both SMC formulations. Contrary to what had been previously reported, shear tests interestingly showed that the shear stress did not vary over a wide range of shear strain. This result is certainly related to the use of a sophisticated shear device that enabled an enhanced control of the kinematics of the shear tests. For a given axial pre-compaction, shear tests also revealed that the shear stress was accompanied with an axial compression stress. The latter is certainly related to the elastic deformation of the bundle network of SMC due to pre-compaction. In addition, these results showed the effect of the strain rate and the fibre content on the rheological response of both SMCs. For these three deformation kinematics, the viscosities of both SMCs were power law functions of the strain rates. The strain rate sensitivity index was similar regardless of the kinematics and showed a shear-thinning behaviour. Further, these viscosities depended on the fibre volume fraction, except the shear viscosity that did not appear to be significantly affected by such variations in the SMC microstructure. These results were used to identify the parameters of a simple tensorial model for SMCs that were seen as purely viscous, transversely isotropic and compressible materials. The originality of this model is that it takes 
into account the compressibility of SMCs. The constitutive parameters of the proposed model were determined using the results of the rheological experiments. The predictions of the model were in good accordance with the experimental results. The model proposed in this study could be easily implemented in finite element code for the simulation of SMC compression moulding.

\section{References}

[1] Orgéas L. and Dumont P.J.J., "Sheet Molding Compounds," Wiley Encycl. Compos., 2012, doi: 10.1002/9781118097298.weoc222.

[2] M. Shirinbayan, J. Fitoussi, F. Meraghni, B. Surowiec, M. Laribi, and A. Tcharkhtchi, "Coupled effect of loading frequency and amplitude on the fatigue behavior of advanced sheet molding compound (A-SMC)," J. Reinf. Plast. Compos., vol. 36, no. 4, pp. 271-282, Jan. 2016, doi: 10.1177/0731684416682853.

[3] M. Péron et al., "PvT-HADDOC: A multi-axial strain analyzer and cure monitoring device for thermoset composites characterization during manufacturing," Compos. Part A Appl. Sci. Manuf., vol. 101, pp. 129-142, 2017, doi: 10.1016/j.compositesa.2017.06.004.

[4] M. Shirinbayan, J. Fitoussi, N. Abbasnezhad, F. Meraghni, B. Surowiec, and A. Tcharkhtchi, "Mechanical characterization of a Low Density Sheet Molding Compound (LD-SMC): Multi-scale damage analysis and strain rate effect," Compos. Part B Eng., vol. 131, pp. 8-20, 2017, doi: 10.1016/j.compositesb.2017.08.004.

[5] D. Ferré Sentis, L. Orgéas, P. J. J. Dumont, S. Rolland du Roscoat, M. Sager, and P. Latil, "3D in situ observations of the compressibility and pore transport in Sheet Moulding Compounds during the early stages of compression moulding," Compos. Part A Appl. Sci. Manuf., vol. 92, pp. 51-61, 2017, doi: 10.1016/j.compositesa.2016.10.031.

[6] D. Ferré Sentis et al., "Tensile behaviour of uncured sheet moulding compounds: Rheology and flow-induced microstructures," Compos. Part A Appl. Sci. Manuf., vol. 101, pp. 459-470, 2017, doi: 10.1016/j.compositesa.2017.07.003.

[7] P. Feraboli, E. Peitso, F. Deleo, T. Cleveland, and P. B. Stickler, "Characterization of prepreg-based discontinuous carbon fiber/epoxy systems," J. Reinf. Plast. Compos., vol. 28, no. 10, pp. 1191-1214, 2009, doi: 10.1177/0731684408088883.

[8] J. Palmer, L. Savage, O. R. Ghita, and K. E. Evans, "Sheet moulding compound (SMC) from carbon fibre recyclate," Compos. Part A Appl. Sci. Manuf., vol. 41, no. 9, pp. 1232-1237, 2010, doi: 10.1016/j.compositesa.2010.05.005.

[9] L. M. Martulli et al., "A thick-walled sheet moulding compound automotive component: Manufacturing and performance," Compos. Part A Appl. Sci. Manuf., vol. 128, no. September 2019, p. 105688, 2020, doi: 10.1016/j.compositesa.2019.105688.

[10] L. M. Martulli, L. Muyshondt, M. Kerschbaum, S. Pimenta, S. V. Lomov, and Y. Swolfs, "Carbon fibre sheet moulding compounds with high in-mould flow: Linking 
morphology to tensile and compressive properties," Compos. Part A Appl. Sci. Manuf., vol. 126, no. June, p. 105600, 2019, doi: 10.1016/j.compositesa.2019.105600.

[11] A. D. Evans, C. C. Qian, T. A. Turner, L. T. Harper, and N. A. Warrior, "Flow characteristics of carbon fibre moulding compounds," Compos. Part A Appl. Sci. Manuf., vol. 90, pp. 1-12, 2016, doi: 10.1016/j.compositesa.2016.06.020.

[12] R. J. Silva-Nieto, B. C. Fisher, and A. W. Birley, "Predicting mold flow for unsaturated polyester resin sheet molding compounds," Polym. Compos., vol. 1, no. 1, pp. 14-23, 1980, doi: doi:10.1002/pc.750010105.

[13] M. R. Barone and D. A. Caulk, "Kinematics of flow in sheet molding compounds," Polym. Compos., vol. 6, no. 2, pp. 105-109, 1985, doi: doi:10.1002/pc.750060208.

[14] J. M. Castro and R. M. Griffith, "Sheet molding compound compression-molding flow," Polym. Eng. Sci., vol. 29, no. 10, pp. 632-638, 1989, doi: 10.1002/pen.760291004.

[15] J. Xu, J. Kim, T. Ho, and L. J. Lee, "Compression molding of sheet molding compounds in plate-rib type geometry," Polym. Compos., vol. 14, no. 1, pp. 51-58, 1993, doi: 10.1002/pc.750140108.

[16] N. E. J. Olsson, T. S. Lundström, and K. Olofsson, "Design of experiment study of compression moulding of SMC," Plast. Rubber Compos., vol. 38, no. 9-10, pp. 426431, 2009, doi: 10.1179/146580109X12540995045886.

[17] G. Alnersson, M. W. Tahir, A. L. Ljung, and T. S. Lundström, "Review of the numerical modeling of compression molding of sheet molding compound," Processes, vol. 8, no. 2, pp. 1-12, 2020, doi: 10.3390/pr8020179.

[18] N. Meyer, L. Schöttl, L. Bretz, A. N. Hrymak, and L. Kärger, "Direct Bundle Simulation approach for the compression molding process of Sheet Molding Compound," Compos. Part A Appl. Sci. Manuf., vol. 132, no. January, p. 105809, 2020, doi: 10.1016/j.compositesa.2020.105809.

[19] R. J. Silva-Nieto, B. C. Fisher, and A. W. Birley, "Rheological characterization of unsaturated polyester resin sheet molding compound," Polym. Eng. Sci., vol. 21, no. 8, pp. 499-506, 1981, doi: 10.1002/pen.760210810.

[20] L. J. Lee, L. F. Marker, and R. M. Griffith, "The rheology and mold flow of polyester sheet molding compound," Polym. Compos., vol. 2, no. 4, pp. 209-218, 1981, doi: 10.1002/pc.750020412.

[21] J. Kim, Y. C. Shiau, L. J. Lee, and Y. T. Im, "Compression Molding Simulation of Chopped Fiber Reinforced Polymeric Composites in Plate-Rib Type Geometry," Polym. Compos., vol. 13, no. 2, pp. 97-107, 1992, doi: doi.org/10.1002/pc.750130205.

[22] K. T. Kim, J. H. Jeong, and Y. T. Im, "Effect of molding parameters on compression molded sheet molding compounds parts," J. Mater. Process. Technol., vol. 67, no. 1-3, pp. 105-111, 1997, doi: 10.1016/S0924-0136(96)02827-0.

[23] C.-M. Lin, C.-I. Weng, and C.-T. Ho, "Anisotropy in sheet molding compounds during compression molding," Polym. Compos., vol. 18, no. 5, pp. 613-622, 1997, doi: doi:10.1002/pc.10312.

[24] C. M. Lin and C. I. Weng, "Simulation of compression molding for sheet molding 
compound considering the anisotropic effect," Polym. Compos., vol. 20, no. 1, pp. 98 113, 1999, doi: 10.1002/pc.10338.

[25] S. Le Corre, L. Orgéas, D. Favier, A. Tourabi, A. Maazouz, and C. Venet, "Shear and compression behaviour of sheet moulding compounds," Compos. Sci. Technol., vol. 62, pp. 571-577, 2002, doi: doi.org/10.1016/S0266-3538(01)00151-8.

[26] P. Dumont, L. Orgéas, S. Le Corre, and D. Favier, "Anisotropic viscous behavior of sheet molding compounds (SMC) during compression molding," Int. J. Plast., vol. 19, no. 5, 2003, doi: 10.1016/S0749-6419(01)00077-8.

[27] S. Le Corre, P. Dumont, L. Orgéas, and D. Favier, "Rheology of highly concentrated planar fiber suspensions," J. Rheol. (N.Y.N.Y)., vol. 49, no. 5, 2005, doi: 10.1122/1.1993594.

[28] O. Guiraud, P. J. J. Dumont, L. Orgéas, J.-P. Vassal, T.-H. Le, and D. Favier, "Towards the simulation of mould filling with polymer composites reinforced with mineral fillers and short fibres," Int. J. Mater. Form., vol. 3, no. S2, pp. 1313-1326, Sep. 2010, doi: 10.1007/s12289-009-0658-7.

[29] O. Guiraud, P. J. J. Dumont, L. Orgéas, and D. Favier, "Rheometry of compression moulded fibre-reinforced polymer composites: Rheology, compressibility, and friction forces with mould surfaces," Compos. Part A Appl. Sci. Manuf., vol. 43, no. 11, 2012, doi: 10.1016/j.compositesa.2012.06.006.

[30] O. Guiraud, P. J. J. Dumont, and L. Orgéas, "How to prepare SMC and BMC-like compounds to perform relevant rheological experiments?," Appl. Compos. Mater., vol. 20, pp. 157-169, 2013, doi: 10.1007/s10443-012-9261-z.

[31] S. Le Corre, D. Caillerie, L. Orgéas, and Favier D., "Behavior of a net of fibers linked by viscous interactions : theory and mechanical properties," J. Mech. Phys. Solids, vol. 52, pp. 395-421, 2004, doi: 10.1016/S0022-5096(03)00090-5.

[32] L. F. Salazar Betancourt, P. Laure, L. Silva, and M. Sager, "Numerical implementation of a rheology model for fiber-reinforced composite and viscous layer approach for friction study," Key Eng. Mater., vol. 651-653, pp. 848-854, 2015, doi: 10.4028/www.scientific.net/KEM.651-653.848.

[33] J. Görthofer et al., "Virtual process chain of sheet molding compound: Development, validation and perspectives," Compos. Part B Eng., vol. 169, no. December 2018, pp. 133-147, 2019, doi: 10.1016/j.compositesb.2019.04.001.

[34] N. E. J. Olsson, L. G. Westerberg, and T. S. Lundström, "Transport of bubbles during compression in a non-Newtonian fluid," in ITP2009 Interdiscip. Transp. Phenom. VI Fluid, Thermal, Biological, Materials and Space Sciences, 2009, pp. 1-12.

[35] K. C. Ortman, N. Agarwal, A. P. R. Eberle, D. G. Baird, P. Wapperom, and A. J. Giacomin, "Transient shear flow behavior of concentrated long glass fiber suspensions in a sliding plate rheometer," J. Nonnewton. Fluid Mech., vol. 166, no. 16, pp. 884895, 2011, doi: 10.1016/j.jnnfm.2011.04.007.

[36] A. C. Caba, A. C. Loos, and C. Batra, "Fiber - fiber interactions in carbon mat thermoplastics," Compos. Part A Appl. Sci. Manuf., vol. 38, pp. 469-483, 2007, doi: 10.1016/j.compositesa.2006.02.024.

[37] M. Hohberg, L. Kärger, F. Henning, and A. Hrymak, "Rheological measurements and 
rheological shell model Considering the compressible behavior of long fiber reinforced sheet molding compound (SMC)," Compos. Part A Appl. Sci. Manuf., vol. 95, pp. 110117, 2017, doi: 10.1016/j.compositesa.2017.01.006.

[38] M. Boulon, G. Armand, N. Hoteit, and P. Divoux, "Experimental investigations and modelling of shearing of calcite healed discontinuities of granodiorite under typical stresses," Eng. Geol., vol. 64, pp. 117-133, 2002, doi: doi.org/10.1016/S00137952(01)00112-0.

[39] P. Dumont, L. Orgéas, D. Favier, P. Pizette, and C. Venet, "Compression moulding of SMC: In situ experiments, modelling and simulation," Compos. Part A Appl. Sci. Manuf., vol. 38, no. 2, pp. 353-368, 2007, doi: 10.1016/j.compositesa.2006.03.010.

[40] O. Guiraud, P. J. J. Dumont, L. Orgéas, and D. Favier, "Rheometry of compression moulded fibre-reinforced polymer composites: Rheology, compressibility, and friction forces with mould surfaces," Compos. Part A Appl. Sci. Manuf., vol. 43, no. 11, pp. 2107-2119, 2012, doi: 10.1016/j.compositesa.2012.06.006.

[41] J. P. Boehler, Applications of tensor functions in solid mechanics. Wien: SpringerVerlag, 1987.

[42] S. Toll and J.-A. E. Månson, "Dynamics of a planar concentrated fiber suspension with non-hydrodynamic interaction," J. Rheol. (N. Y. N. Y)., vol. 38, no. 4, pp. 985-997, 1994, doi: 10.1122/1.550539.

[43] C. Servais, A. Luciani, and J.-A. E. Månson, "Fiber - fiber interaction in concentrated suspensions : Dispersed fiber bundles Fiber - fiber interaction in concentrated suspensions : Dispersed fiber bundles," J. Rheol. (N. Y. N. Y)., vol. 43, no. 4, pp. 10051018, 1999, doi: 10.1122/1.551015.

[44] S. Toll, "Note: On the tube model for fiber suspensions," J. Rheol. (N. Y. N. Y)., vol. 37, no. 1, pp. 123-125, 1993, doi: 10.1122/1.550460.

[45] L. Orgéas, P. J. J. Dumont, J.-P. Vassal, O. Guiraud, V. Michaud, and D. Favier, "Inplane conduction of polymer composite plates reinforced with architectured networks of Copper fibres," J. Mater. Sci., vol. 47, pp. 2932-2942, 2012, doi: 10.1007/s10853011-6126-z.

[46] O. Guiraud, L. Orgéas, P. J. J. Dumont, and S. Rolland du Roscoat, "Microstructure and deformation micromechanisms of concentrated fiber bundle suspensions: An analysis combining x-ray microtomography and pull-out tests," J. Rheol. (N. Y. N. Y)., vol. 56, no. 3, pp. 593-623, May 2012, doi: 10.1122/1.3698185.

[47] P. J. J. Dumont, S. Le Corre, L. Orgéas, and D. Favier, “A numerical analysis of the evolution of bundle orientation in concentrated fibre-bundle suspensions," $J$.

Nonnewton. Fluid Mech., vol. 160, no. 2-3, 2009, doi: 10.1016/j.jnnfm.2009.03.001. 
Table 1. Values of the constitutive parameters for the S and H SMC formulations.

\begin{tabular}{cll}
\hline Parameters & S formulation & H formulation \\
\hline $\boldsymbol{L}$ & 20 & 10 \\
$\boldsymbol{\phi}_{\mathbf{c}}$ & 0.02 & 0.02 \\
$\boldsymbol{n}$ & 0.42 & 0.35 \\
$\boldsymbol{\eta}_{\mathbf{0}}$ & $1.3 \times 10^{8} \mathrm{~Pa} \mathrm{~s}^{\mathrm{n}}$ & $2.2 \times 10^{7} \mathrm{~Pa} \mathrm{~s}$ \\
$\boldsymbol{\delta}$ & $5.10^{5}$ & $1.10^{5}$ \\
$\boldsymbol{\beta}$ & 0.0001 & 0.0003 \\
$\boldsymbol{\alpha}_{\mathbf{3}}^{\mathbf{0}}$ & 0.1 & 0.05 \\
$\boldsymbol{\varphi}_{\mathbf{f}}$ & 0.23 & 0.38 \\
\hline
\end{tabular}



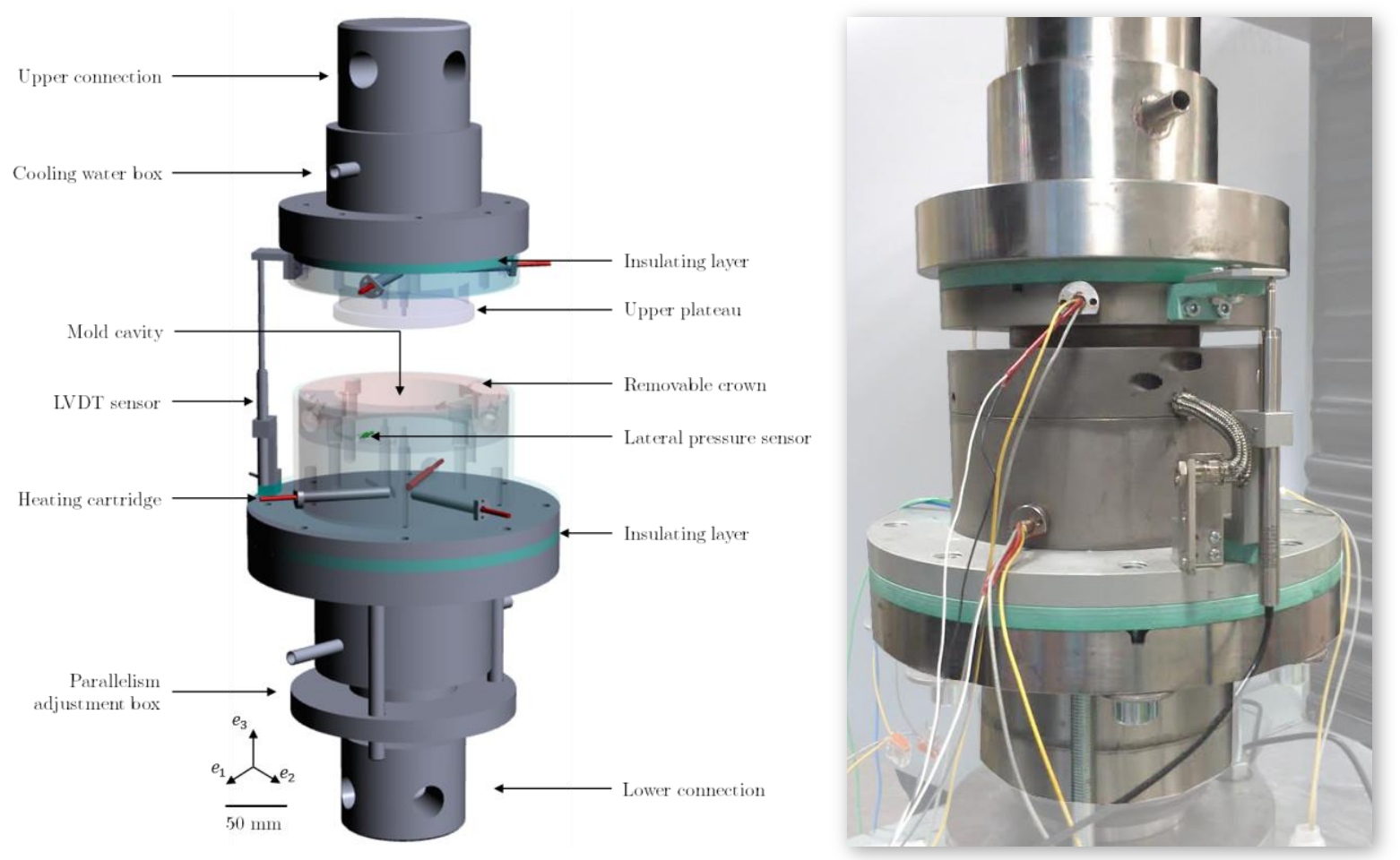

Figure 1. Compression device designed for œdometric compression experiments: schematic view (left), actual device (right).
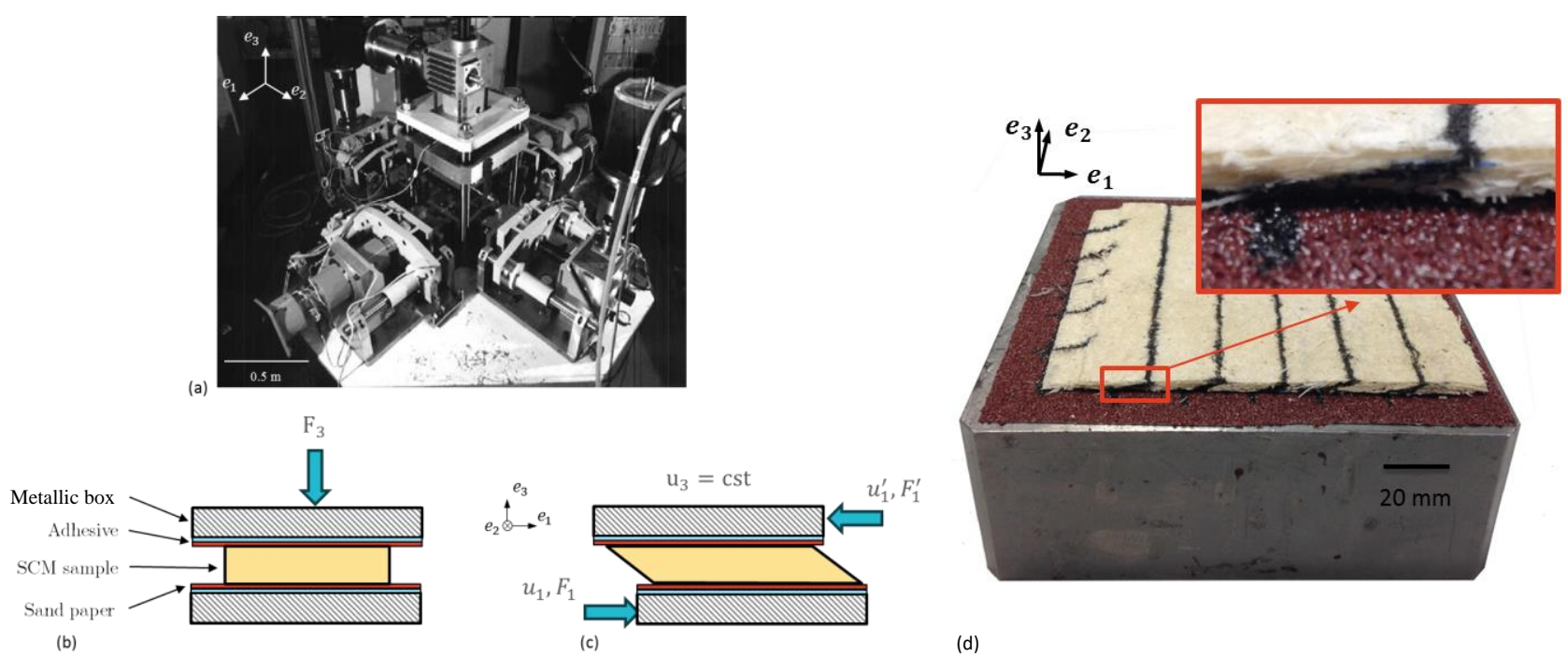

Figure 2. (a) Triaxial BCR3D shear device [38]. (b) and (c) Sketches showing the principle of shear experiment. (d) Photograph of a sheared sample. Inset: zoom on vertical lines and horizontal lines that were drawn on the side walls of the SMC sample and on the sandpaper surface, respectively. 

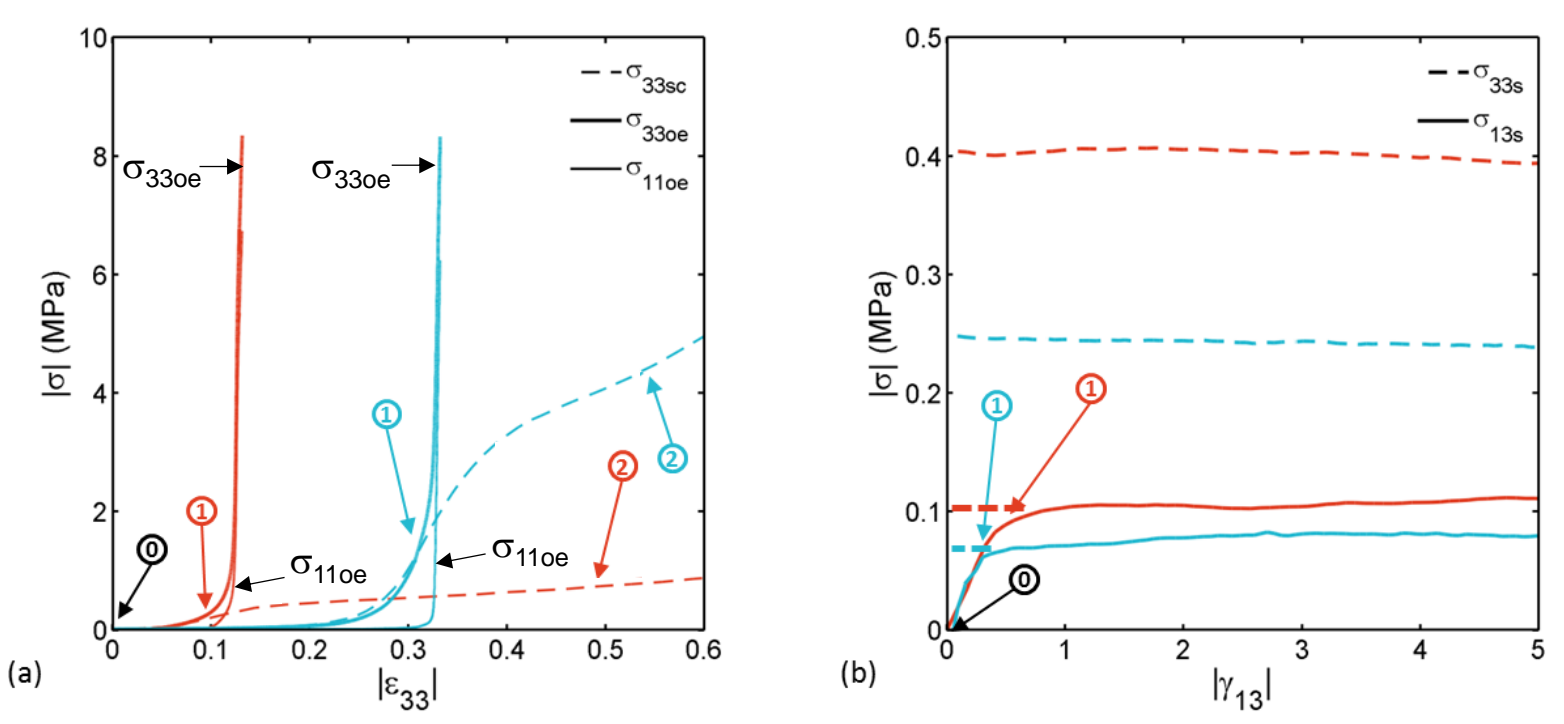

Figure 3. (a) Typical simple (dotted lines) and œdometric (continuous lines) compression experiments at an axial strain rate $D_{33}=10^{-3} \mathrm{~s}^{-1}$. (b) Typical shear experiment at a shear strain rate $D_{13}=4.10^{-2} \mathrm{~s}^{-1}$. Red curves: $\mathrm{S}$ formulation, blue curves: $\mathrm{H}$ formulation.

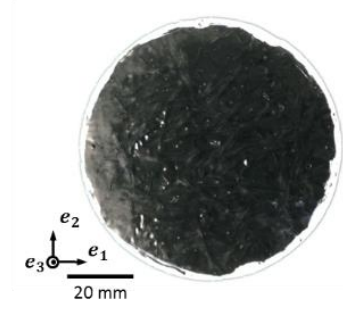

(a)

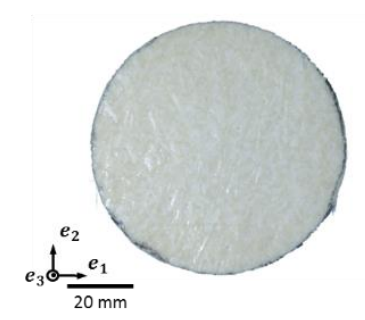

(c)
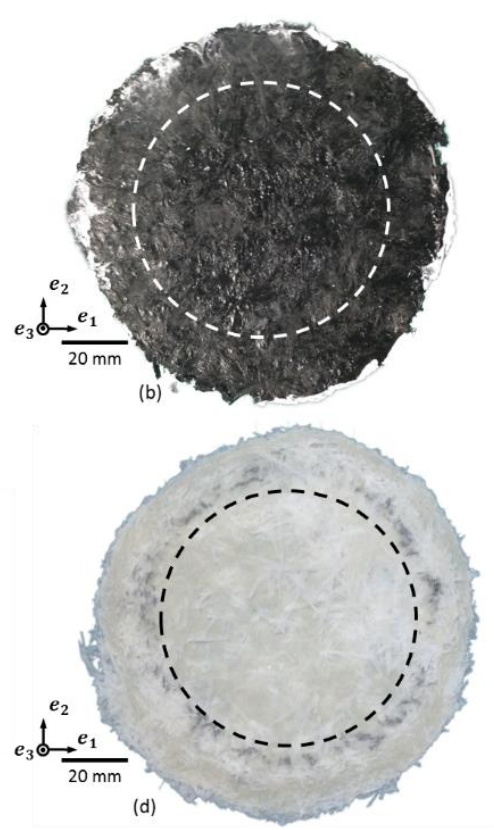

Figure 4. Aspect of simple compression samples for the $\mathrm{S}$ formulation (a) in the initial state and (b) at the end of the test. Aspect of simple compression samples for the $\mathrm{H}$ formulation (c) in the initial state and (d) at the end of the test. Dotted lines represent the initial position of the painted-lines. 


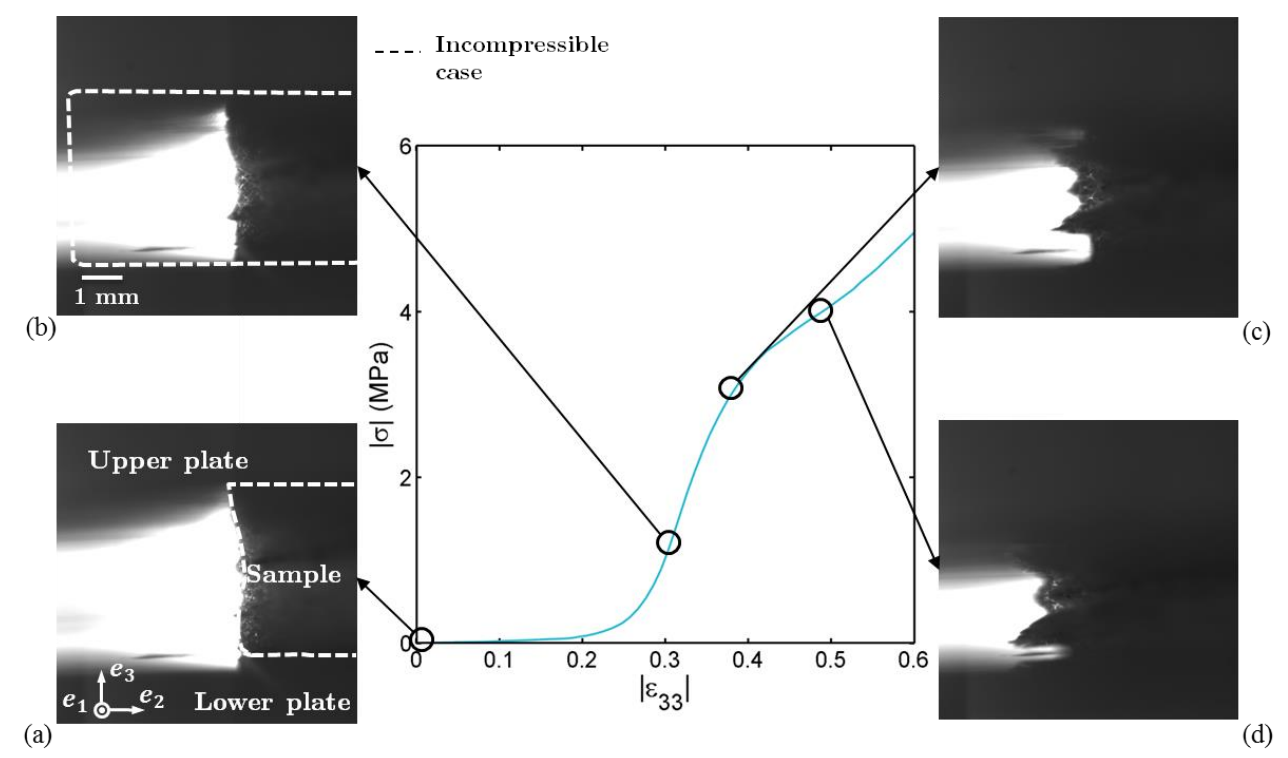

Figure 5. Optical micrographs showing a side view of an H-SMC specimen during a simple compression test at an axial strain rate $D_{33}=10^{-3} \mathrm{~s}^{-1}$ at an axial strain $\left|\varepsilon_{33}\right|$ equal to (a) 0 , (b) 0.3 , (c) 0.41 , (d) 0.47 .
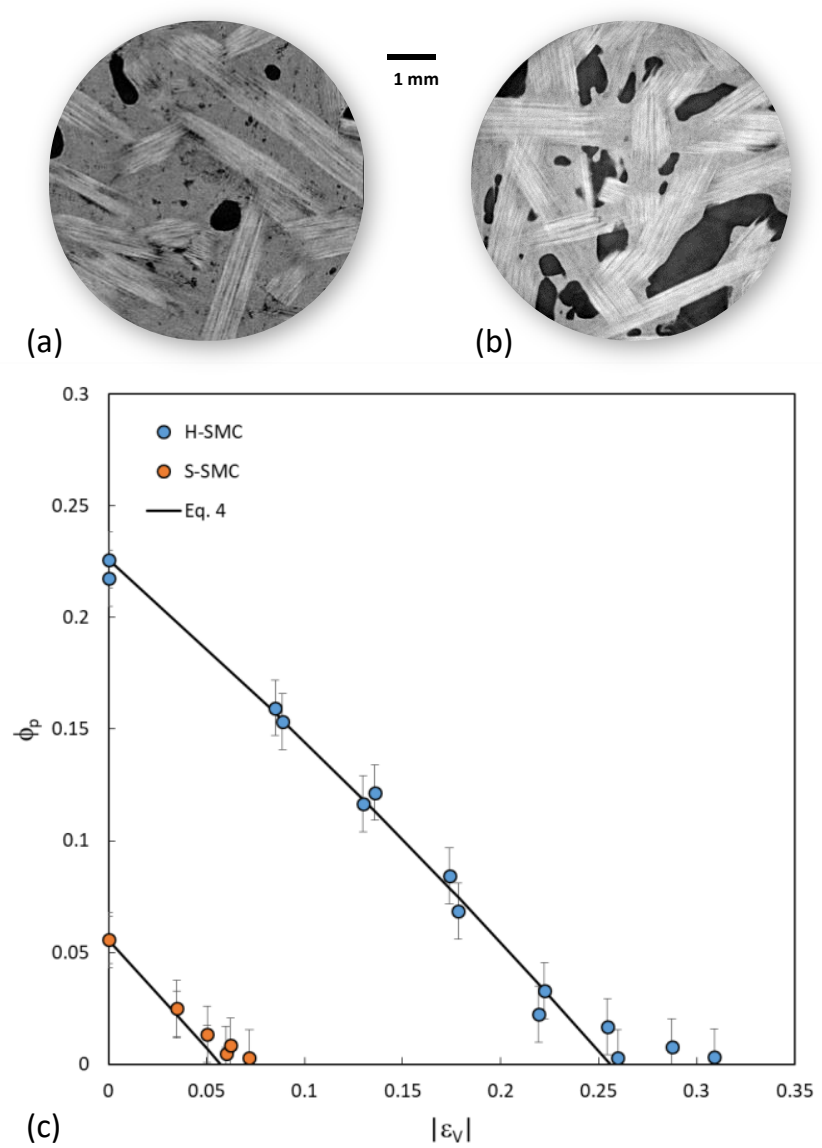
Figure 6. Views of cross-sections in the $\left(\boldsymbol{e}_{1}, \boldsymbol{e}_{2}\right)$-plane of 3D X-ray microtomography images (beamline BM05, ESRF, Grenoble, France) of (a) a S SMC and (b) a H SMC specimens. In black: pores, in medium-grey levels: polymer paste, and light grey levels: glass fibre bundles. (c) Evolution of the porosity $\phi_{\mathrm{p}}$ as a function of the volumetric strain $\left|\varepsilon_{V}\right|$ for the $\mathrm{S}$ and $\mathrm{H}$ formulations during simple compression using experimental data provided in [5] as well as the predictions of Eq. 5.
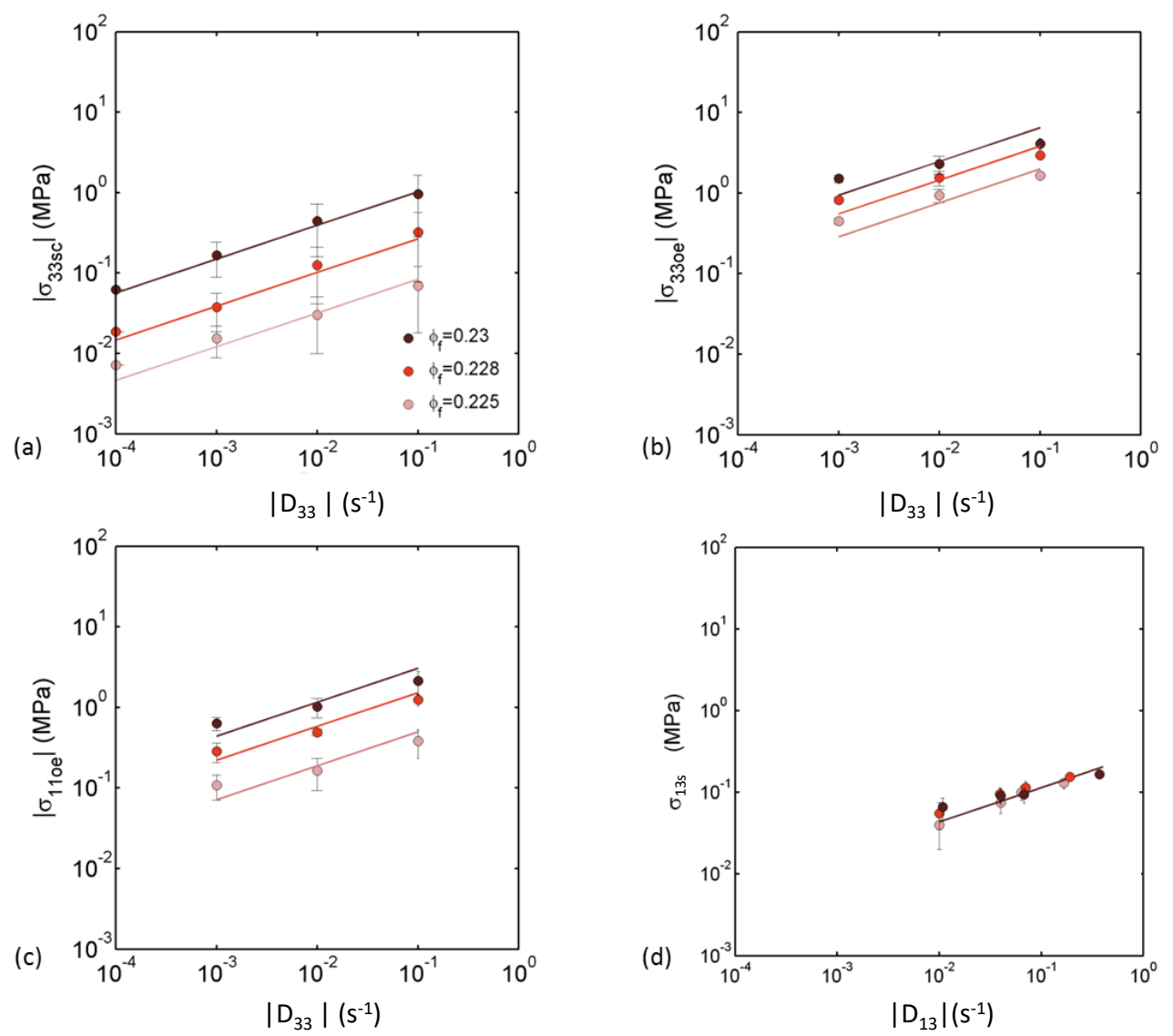

Figure 7. Influence of the strain rate on stress levels for various fibre contents $\phi_{\mathrm{f}}$ for (a) simple compression, (b) and (c) œdometric compression and (d) shear tests for the S formulation. 

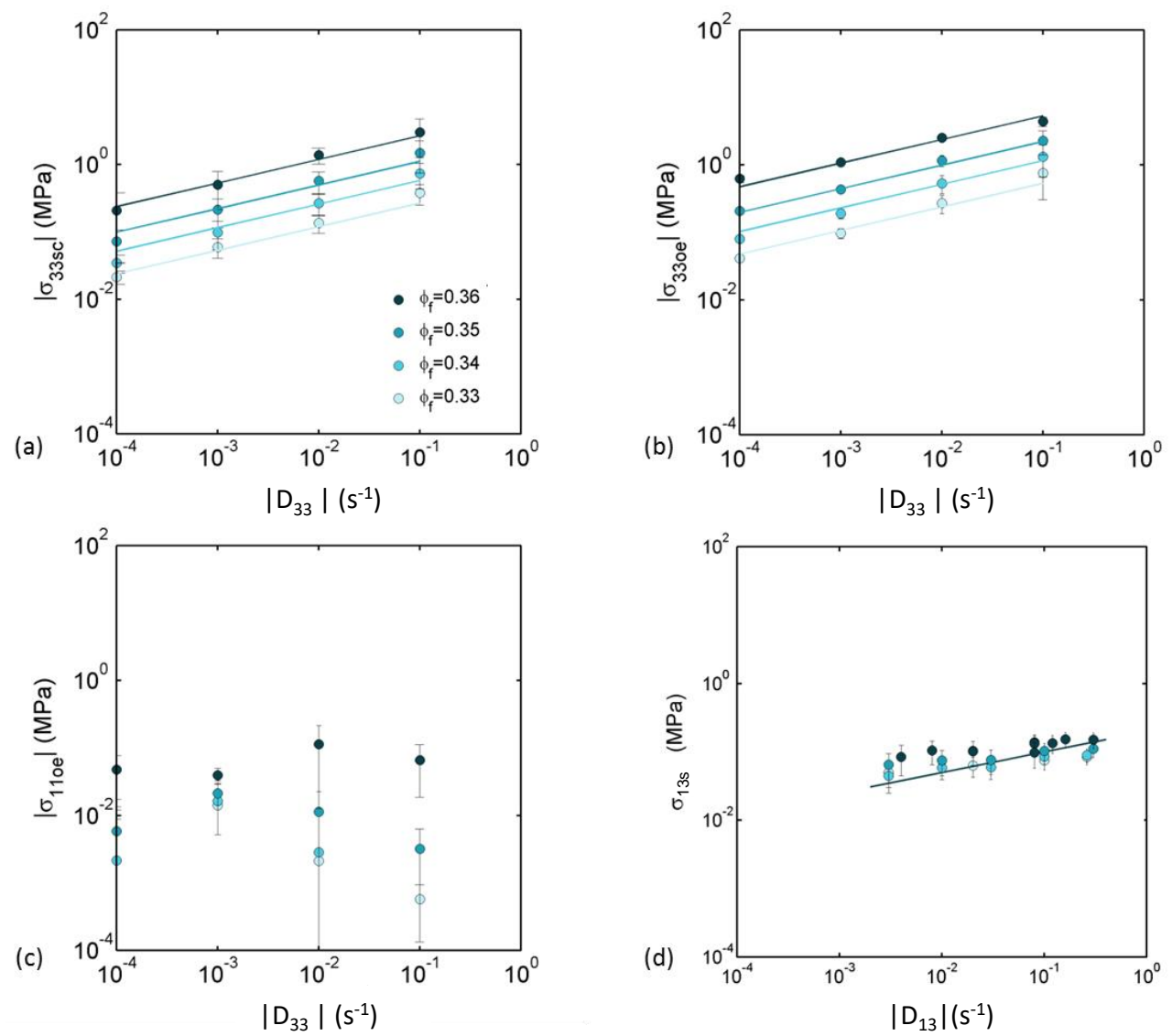

Figure 8. Influence of the strain rate on stress levels for various fibre contents $\phi_{\mathrm{f}}$ and for (a) simple compression, (b) and (c) œedometric compression and (d) shear tests for the $\mathrm{H}$ formulation.
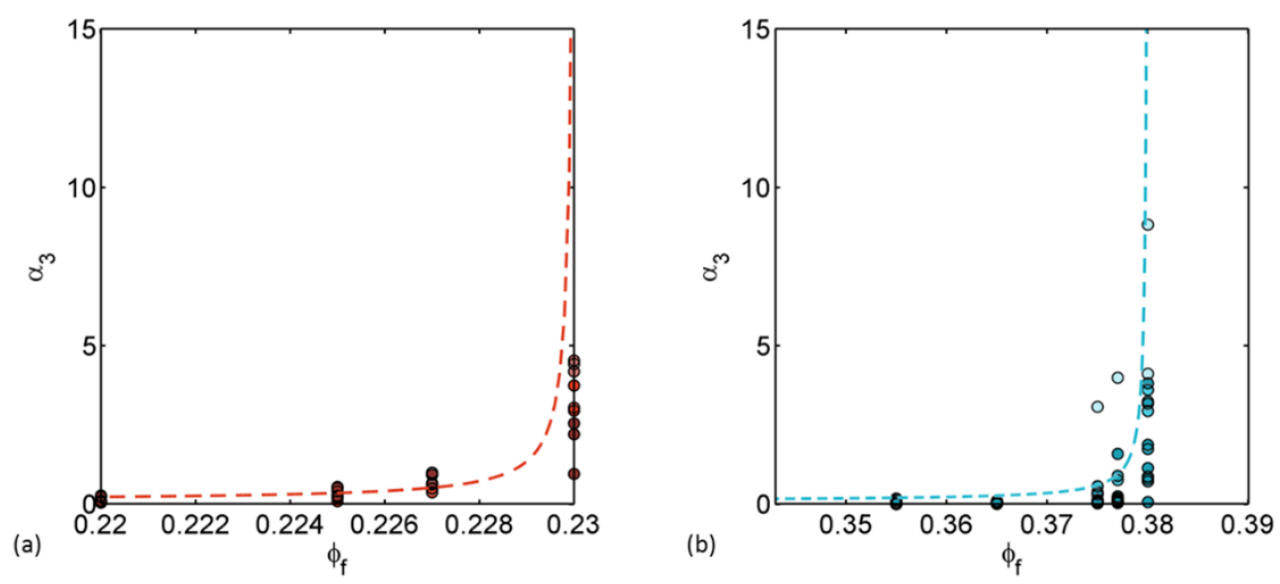

Figure 9. Evolution of the rheological function $\alpha_{3}$ as a function of the fibre volume fraction $\phi_{\mathrm{f}}$ for (a) the $\mathrm{S}$ formulation and (b) the $\mathrm{H}$ formulation, respectively. Markers represent experimental measurements and dotted lines represent the values given by Eq. 17 . 

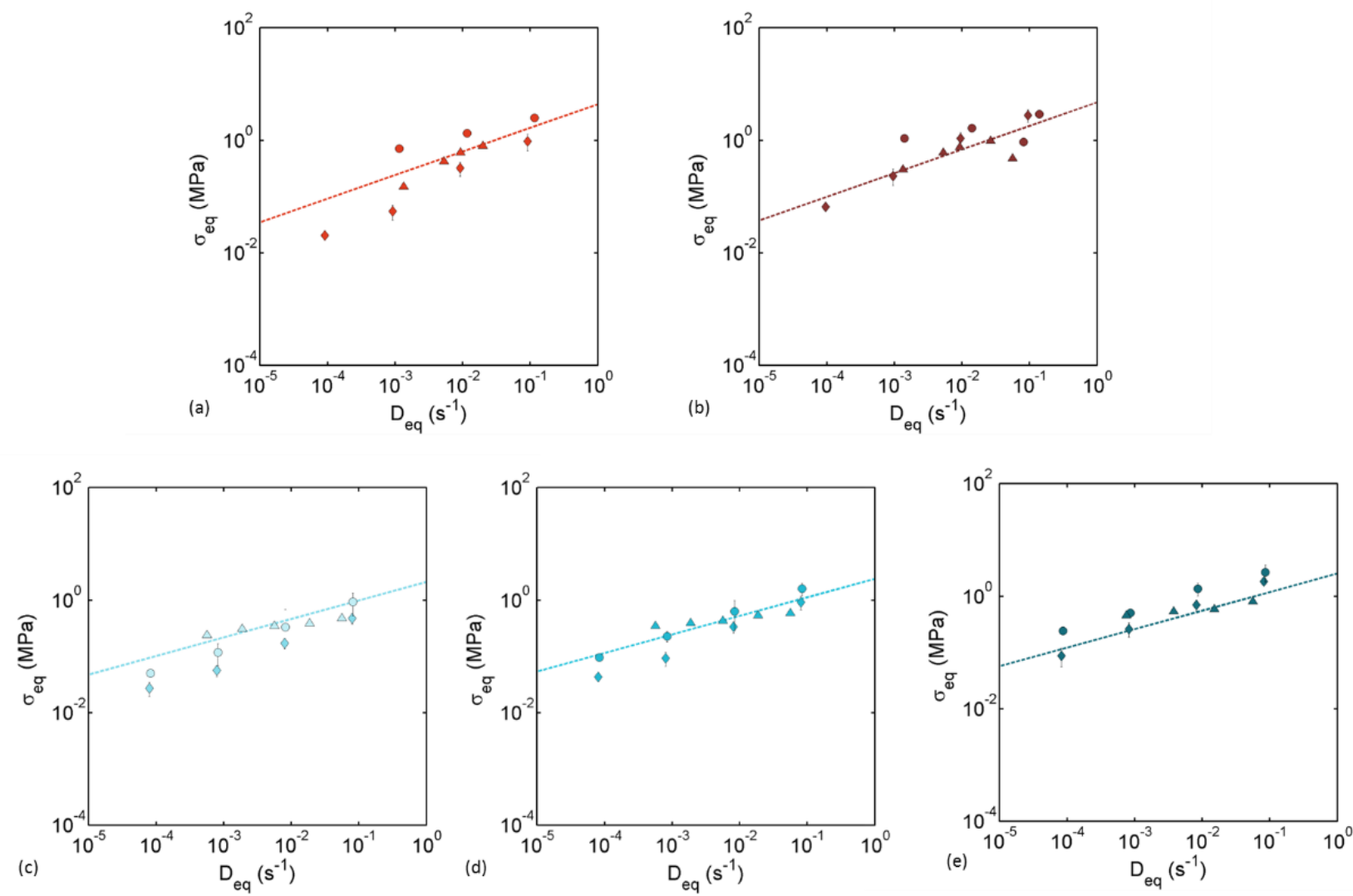

Figure 10. Comparison between the experimental results and the model predictions for the evolution of the equivalent stress $\sigma_{e q}$ as a function of the equivalent strain rate $D_{e q}$, for the $\mathrm{S}$ formulation for (a) $\phi_{\mathrm{f}}=0.227$ and (b) $\phi_{\mathrm{f}}=0.228$, and for the $\mathrm{H}$ formulation for (c) $\phi_{\mathrm{f}}=$ 0.34 (d) $\phi_{\mathrm{f}}=0.35$, and (e) $\phi_{\mathrm{f}}=0.36$. Diamonds represent results of simple compression experiments, circles represent œdometric compression results and triangles represent shear test results. The dotted lines are the predictions of the model. 

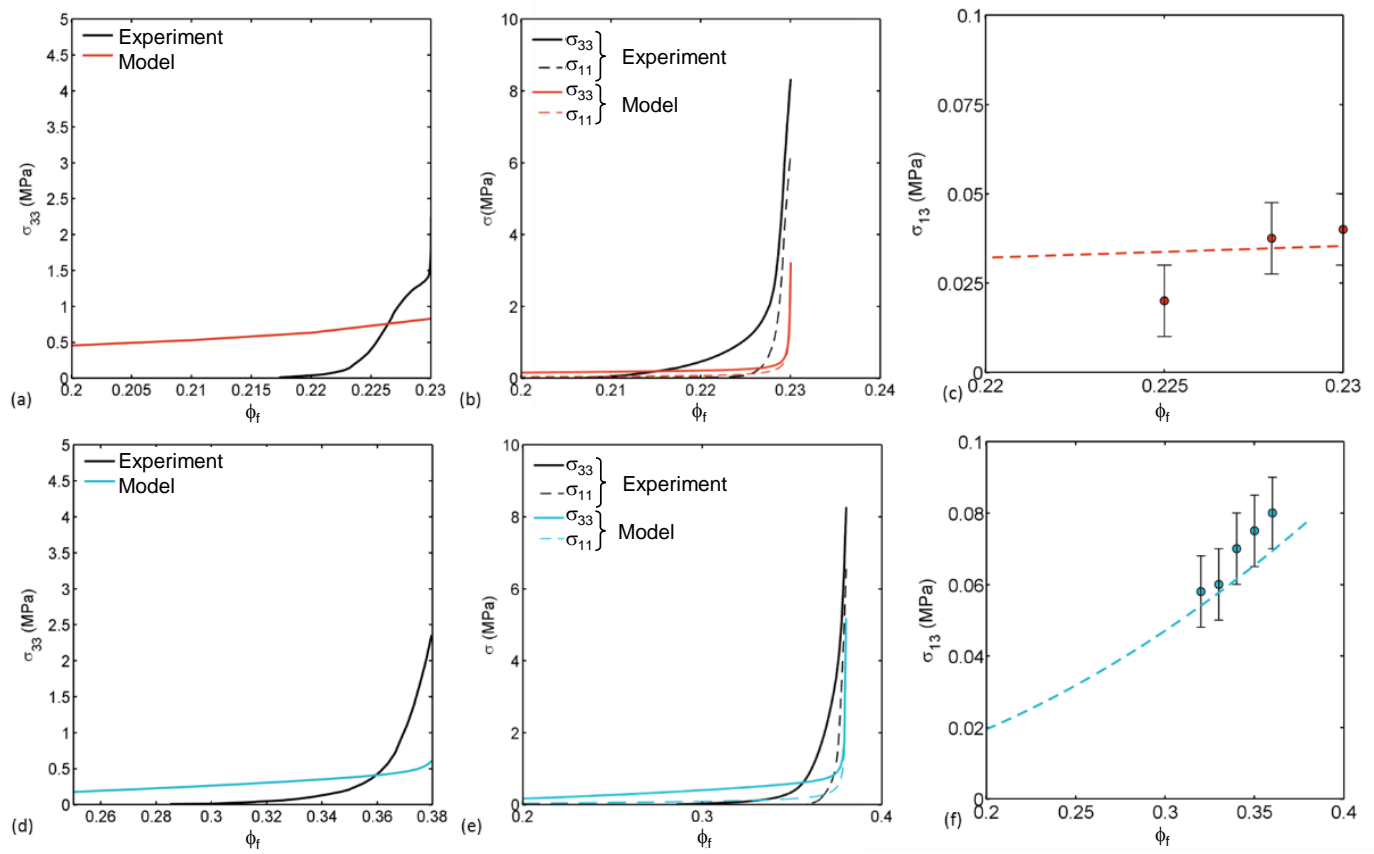

Figure 11. Comparison between the model predictions and the experimental results obtained for axial and shear strain rates $D_{33}=10^{-2} \mathrm{~s}^{-1}$ and $D_{13}=10^{-2} \mathrm{~s}^{-1}$ for $(\mathrm{a}, \mathrm{d})$ simple compression, (b,e) œdometric compression and (c,f) shear tests for the $\mathrm{S}$ and $\mathrm{H}$ formulations, respectively (dots represent experimental data). The red or blue continuous and dotted lines are the predictions of the model for the $\mathrm{S}$ formulation or $\mathrm{H}$ formulation, respectively. 